\title{
A luta entre a Dama de Negro e a Dama de Branco: cuidados de Enfermagem na terminalidade
}

\author{
The fight between The Lady in Black and The Lady in White: nursing care in terminally ill patients
}

Luã Gianine Moreira*, Eliara Adelino da Silva, Thiago Augusto Monteiro da Silva

\begin{abstract}
Resumo
Trata-se de um estudo baseado no relato de experiência da percepção do acadêmico de enfermagem sobre os cuidados paliativos e terminalidade. Os objetivos foram relatar os conflitos vivenciados pelo autor deste estudo frente ao cuidado paliativo com um familiar e paciente oncológico; Descrever as contribuições deste cuidado para a família e paciente diante do sofrimento, tratamento da dor, alívio dos sintomas, apoio emocional e social; Descrever os dilemas vivenciados pelo autor diante da terminalidade do seu ente querido. O estudo utilizou um método qualitativo, descritivo, dividido em etapas: levantamento de referências bibliográficas com o propósito de embasar e nortear o relato a ser desenvolvido, contextualizando a experiência com as Teorias do Cuidado Humano de Jean Watson e Cecília Saunders, seguido de uma análise interpretativa do autor diante dos cuidados paliativos oferecidos ao seu familiar. Durante esta vivência, o autor enfrentou fatores que modificaram suas percepções do cuidado paliativo, incluindo a peregrinação em busca de respostas, turbulências e conflitos familiares referentes ao prognóstico médico e dificuldades de se tornar alicerce para os familiares em relação ao suporte emocional, socioeconômico e espiritual na reconstrução de paradigmas, repensando assim a terminalidade. Este estudo possibilitou um olhar diferenciado sobre a terminalidade e a existência da subjetividade presentes no processo morte-morrer, vinculado a humanização da assistência prestada.
\end{abstract}

Palavras-chave: Enfermagem; Cuidados Paliativos; Família; Saúde.

LG, Silva EA, Silva TAM. A luta entre a Dama de Negro e a Dama de Branco: cuidados de Enfermagem na terminalidade. Revista de Saúde. 2016 Jan./Jun.; $07 \quad$ (1): 39-41.

\begin{abstract}
This study is based on the perception of a nursing student regarding the experience of palliative care and terminal illness of a family member. This study reports the conflicts experienced by the author of the study during the palliative care of his father as an oncology patient and describes the dilemmas experienced by the author in the face of the terminal illness of a loved family member; describes the importance of the care provided for the family and patient in the face of suffering, including pain management, symptom relief, emotional and social support. A qualitative, descriptive method was used, and the study was divided into steps: literature review to provide a background and contextualize the case described within the Theories of Human Caring by Jean Watson and Cecilia Saunders, followed by an interpretative description of the experience involved in the palliative care offered to the author's family. During this experience, the author faced factors and situations which changed his perceptions of palliative care, the pilgrimage for answers, family turmoil and conflicts between the medical prognosis, patient care, and difficulties in becoming the family's foundation for emotional, socio-economic, and spiritual support. The experience enabled a reconstruction of paradigms, as well rethinking palliative care and terminality, providing a different perspective on the subjectivity of the process of death/ dying, attached to the humanization of the care provided.

Keywords: Nursing; Palliative care; Family; Health.
\end{abstract}

\section{Introdução}

De acordo com a Organização Mundial de Saúde (OMS), cuidados paliativos consistem na assistência promovida por uma equipe multidisciplinar, que objetiva a melhoria da qualidade de vida do binômio cliente-família, diante de uma doença que ameace a vida, por meio da prevenção e alívio do sofrimento, da identificação precoce, avaliação impecável e tratamento de dor e demais sintomas físicos, sociais, psicológicos e espirituais. ${ }^{1}$

No Brasil, iniciativas isoladas e discussões a respeito dos cuidados paliativos são debatidas desde os anos 1970. Mas apenas a partir dos anos 1990 é que começaram a aparecer os primeiros serviços organizados, mas de forma experimental, diante de tais premissas relacionadas aos cuidados paliativos frente a uma doença que ameace a vida de um cliente fora de possibilidade de terapêutica. ${ }^{2}$

Os objetivos do presente estudo são relatar os conflitos vivenciados por um acadêmico de enfermagem frente ao cuidado paliativo com um familiar e paciente oncológico, descrever quais as contribuições que o cuidado paliativo pode ofertar ao binômio clientefamília diante do sofrimento, tratamento da dor, alívio dos sintomas, apoio emocional e social e descrever os dilemas vivenciados diante da terminalidade.

Afiliação dos autores: Universidade Severino Sombra, Pró-Reitoria de Ciências da Saúde e Humanas, Curso de Enfermagem, Vassouras-RJ, Brasil.

*Endereço para correspondência: Universidade Severino Sombra, Av. Exped. Oswaldo de Almeida Ramos, 280 - Centro - Vassouras, RJ - CEP $27700-000$.

E-mail: gianine_moreira@hotmail.com 


\section{Materiais e Métodos}

O método utilizado foi um estudo qualitativo, que representa uma atividade da ciência, que visa a construção da realidade, mas que se preocupa com as ciências sociais em um nível de realidade que não pode ou não deveria ser quantificado. ${ }^{3}$

A primeira etapa deste estudo foi o levantamento de materiais bibliográficos com o propósito de embasar e nortear o relato a ser desenvolvido, possibilitando enriquecimento e contribuição da cientificidade na temática apresentada.

Para este levantamento utilizaram-se artigos indexados na BVS (Biblioteca Virtual em Saúde, Scielo e Lilacs).

A revisão integrativa de literatura teve papel fundamental no estudo, pois foi através dela que se pôde situar o conteúdo na área de pesquisa contextualizando com as teorias do cuidado humano de Jean Watson e Cecília Saunders, que oferecem o alicerce para a visão do cuidar vivenciado pelo autor deste relato durante os cuidados ofertados ao cliente na terminalidade. ${ }^{4}$

A escolha de Watson como teórica justifica-se por esta acreditar que o enfermeiro deve oferecer o cuidado com envolvimento e participação, auxiliando a pessoa a obter controle, dando-lhe autonomia e liberdade, proporcionando autocontrole e autoconhecimento para que promova modificações na sua saúde. ${ }^{5}$

\section{Relato da experiência}

O início da sintomatologia clínica começou em um feriado no ano de 2014, quando o pai do autor apresentou um quadro febril em seu segundo dia de estadia na casa de sua mãe em Minas Gerais.

Após chegar à cidade onde residia o pai do autor teve um diagnóstico médico de Sarampo, por apresentar sintomatologia condizente a doença. Após passadas duas semanas e o quadro febril persistir sem resolução, se iniciou a peregrinação em buscas de respostas.

Seu pai começou a passar por diversos médicos, onde realizou vários exames, sendo encaminhado para um oncologista devido à suspeita de um tumor na glândula adrenal. Ao chegar ao oncologista, este descartou esta possibilidade, dizendo que seu pai estaria com hepatite, mesmo considerando o exame negativo para esta enfermidade. $\mathrm{O}$ paciente foi encaminhando para um gastroentorologista em uma cidade vizinha, o qual suspeitou de uma tumoração.

Então o autor percebeu que entrara em conflitos familiares, pois cada componente de sua família tinha uma percepção e opiniões diferentes, ou seja, cada um vivenciara de modo diferente as fases do luto (negação, raiva, barganha, depressão e aceitação). ${ }^{6}$

A partir deste momento o autor levou o seu saudoso pai para internação em um hospital de uma cidade vizinha, onde o diagnóstico médico de tumoração foi confirmado, fazendo com que o autor se sentisse amargurado, "sem chão", pois sabia que o quadro de seu pai era grave e que teria que explicar da melhor forma para sua mãe.

Neste momento o autor começou a vivenciar as turbulências e os conflitos familiares diante do prognóstico médico, já que seu pai poderia estar até com AIDS, que o autor estaria querendo matar seu pai por deixá-lo naquele hospital e, referente a estes acontecimentos, o autor se questionava até onde ele poderia ir como filho? Como ele deveria agir sem deixar seu saudoso pai mais "para baixo"? Como trabalhar esta baixa autoestima que o seu familiar apresentava?

Após ter vivenciado tais turbulências e o autor se viu com dificuldade em se tornar o alicerce familiar, pois foi o momento em que ele se viu com mais conflitos internos e não se sentiu preparado para tal situação, entrando em desespero por ver que o prognóstico de seu pai não melhorava, sentindo-se desamparado, pedindo a Deus para que fosse feito o melhor para seu pai.

Após o óbito de seu pai no dia 05 de agosto, o autor obteve uma nova percepção do que é a terminalidade.

Vivenciar tal experiência fez o autor refletir sobre o tratamento paliativo e sobre a terminalidade, podendo compreender melhor cada um que se encontra em estágio terminal, percebendo, assim, suas aflições, medos e suas vontades a fim de atender as necessidades humanas/básicas dos pacientes.

\section{Resultados e Discussão}

É fundamental conhecer as expectativas de clientes em cuidados paliativos emrelaçãoà comunicação com os profissionais de enfermagem. $\mathrm{O}$ relacionamento interpessoal é um fator essencial para aqueles que vivenciaram a terminalidade. A comunicação ocupa um lugar de destaque no processo de morrer. Assim, para quem trabalha com seres humanos em situações de doenças que tem a morte anunciada, torna-se essencial saber quando e o que falar, calar e escutar, estar próximo e acessível às necessidades do paciente. ${ }^{7}$

O diálogo é o caminho para atingir esse entendimento, e a comunicação não é simplesmente um dom natural, mas sim cada vez mais entendida como uma habilidade específica que pode ser estudada e melhorada. $^{8}$

Sendo assim, a comunicação é considerada fundamental na assistência à saúde, em especial no que diz respeito aos cuidados paliativos, onde a comunicação é parte do cuidado de saúde, pois ela se relaciona com as decisões tomadas e também com a saúde e a qualidade de vida das pessoas envolvidas, especialmente em situações delicadas como as que dizem respeito ao fim 
da vida. ${ }^{9}$

Falar de morte e de vida é falar de muitas dúvidas que afligem o espírito, aguçam os pensamentos e aumentam as angústias e reflexões e subjetividades que reportam aos conceitos da Dama de Branco, definida como ciência humana, portanto de pessoas e experiências, com um conhecimento, fundamentações e práticas que abrangem o estado de saúde e o estado de doença, e tem um compromisso com a vida através do seus cuidados, e a Dama de Negro, que é definida, então, como situação de perigo, alívio da dor que coloca em jogo o viver, no plano que estamos habituados a entender (religiosidade) não precisando de aliados para vencer a batalha. ${ }^{10}$

É conviver com os opostos como "o branco e o preto", a força e a fraqueza, o abstrato e o concreto, o objetivo e o subjetivo, o racional e o irracional, o sensitivo, o corporal e o espiritual.

A forma, o jeito como o cuidado de enfermagem é feito pode constituir uma ação terapêutica capaz de curar, de retirar alguém de uma profunda depressão, de uma condição complexa de risco, ou até mesmo evitar a sua morte e manter a sua vida.

Durante a vivência, o autor enfrentou fatores que modificaramsuaspercepçõesdocuidadopaliativoeacerca da peregrinação em busca de respostas, turbulências e conflitos familiares quanto ao prognóstico médico e dificuldades de se tornar alicerce para os familiares em relação ao suporte emocional, socioeconômico e espiritual, na reconstrução de paradigmas, repensando assim a terminalidade (Figura 1).

\section{Considerações Finais}

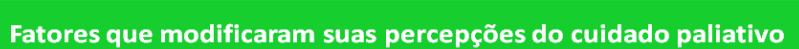

Turbulências

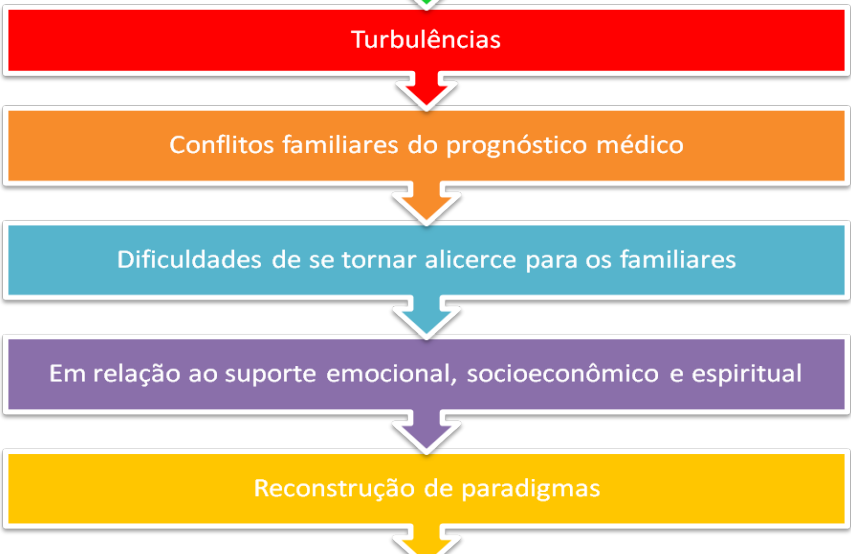

Repensando a terminalidade

Percebeu ainda que, no âmbito familiar, conversar sobre a morte repercutia num certo constrangimento para os familiares, pois, segundo este, a presença da Dama de Branco e da Dama de Negro surge em diversas fases, desde o processo de internação até o findar da vida.

Em muitos momentos foram percebidas a necessidade pela busca de motivos, explicações a fim de fugir da real situação e outras a necessidade de ancorar-se nas realidades apresentadas pelo adoecimento e a própria terminalidade, focando na qualidade de vida para seu ente querido.

Este, por último, defendido como a Dama de Branco, faz do profissional que atua junto aos pacientes fora de possibilidade terapêutica um alicerce para a família que necessita muito mais que diagnósticos e explicações, mas estende-se ao olhar humanizado, holístico, atendendo todas as dimensões do ser que se apresenta a sua frente.

\section{Declarações}

Os autores não possuem conflitos de interesse diretos ou indiretos. A fonte de financiamento desta pesquisa não foi declarada.

\section{Referências}

1. BRASIL, Ministério da Saúde. Cuidados Paliativos. Instituto Nacional de Câncer (INCA). Ministério da Saúde. RJ. 2015. Disponível em: < http:// www1.inca.gov.br/conteudo_view.asp?ID=474> Acesso 06 mar. 2015.

2. ANCP, Academia Nacional de Cuidados Paliativos. O que são cuidados paliativos? SP. ANCP, 2012. Disponível em: <http://www.paliativo.org.br/ ancp.php? $\mathrm{p}=$ oqueecuidados $>$ Acesso 06 mar. 2015.

3. Minayo, M. C. D. S., Deslandes, S. F., Cruz Neto, O., \& Gomes, R. (2013). Pesquisa social: teoria, método e criatividade. Vozes.

4. Richmond, C. (2005). Dame Cicely Saunders. BMJ : British Medical Journal, 331(7510), 238.

5. Watson, J., \& Woodward, T. K. (2010). Jean Watson's theory of human caring. Nursing theories and nursing practice, 3, 351-369.

6. Susaki, T. T., Silva, M. J. P. D., \& Possari, J. F. (2006). Identificação das fases do processo de morrer pelos profissionais de Enfermagem. Acta paul. enferm., São Paulo, 19(2), 144-149.

7. Rodrigues, I. G., \& Zago, M. M. F. (2012). A morte e o morrer: maior desafio de uma equipe de cuidados paliativos-doi: 10.4025/cienccuidsaude. v11i5. 17050. Ciência, Cuidado e Saúde, 11(5), 031-038.

8. Araújo, M. M. T. D., \& Silva, M. J. P. D. (2007). A comunicação com o paciente em cuidados paliativos: valorizando a alegria e o otimismo. Revista da Escola de Enfermagem da USP, 41(4), 668-674.

9. De Andrade, C. G., da Costa, S. F. G., \& Lopes, M. E. L. (2013). Cuidados paliativos: a comunicação como estratégia de cuidado para o paciente em fase terminal. Revista Ciência \& Saúde Coletiva, 18(9).

10. Figueiredo, N. M. A. D., Machado, W. C. A., \& Porto, I. S. (1995). Dama de Negro X Dama de Branco: o cuidado na fronteira vida/morte. Revista de Enfermagem UERJ, 3(2), 139-49.

Figura 1. Vivência do autor. 